https://artnodes.uoc.edu

\title{
Imaginaciones de la evolución de los cuerpos: apuntes sobre las relaciones entre plantas y humanos
}

\author{
Mayra Citlalli Rojo Gómez \\ Artista-investigadora independiente \\ Fecha de presentación: septiembre de 2020 \\ Fecha de aceptación: diciembre de 2020 \\ Fecha de publicación: enero de 2021
}

\section{Cita recomendada}

Citlalli Rojo Gómez, Mayra. 2021. «Imaginaciones de la evolución de los cuerpos: apuntes sobre las relaciones entre plantas y humanos». En: Benítez, Laura; Berger, Erich (coord.) «Artes en tiempos de pandemia». Artnodes, núm. 27: 1-9. UOC. [Consulta: dd/mm/aa]. http:// doi.org/10.7238/a.v0i27.373929

\footnotetext{
Los textos publicados en esta revista están sujetos -si no se indica lo contrario- a una licencia de
Reconocimiento 4.0 Internacional de CreativeCommons. La licencia completa se puede consultar en https://creativecommons.org/licenses/by/4.0/deed.es_ES.
}

\section{Resumen \\ Este texto se aproxima a la relación entre la domesticación de las plantas y el desorden establecido por la actual pandemia mediante la problematización entre una poética de la hibridación, una política de la dependencia y el cuidado que genera la práctica del injerto vegetal. Asimismo, hace una aproximación a la historia y al rastreo de otras formas de concepción y enunciación del cuerpo y el entorno en el contexto y pensamiento de los pueblos originarios, particularmente se toma la noción y la palabra otomí, Nzaki, «árbol de sangre», como exploración discursiva y artística sobre el rastreo de nuevos parentescos con las plantas domésticas.}

\section{Palabras clave}

Saintpaulia, Huernia, injertos vegetales, evolución, cuerpo, decolonial, Nzaki. 


\title{
artnodes
}

https://artnodes.uoc.edu

Imaginaciones de la evolución de los cuerpos: apuntes sobre las relaciones entre plantas y humanos

\section{Imaginations of the evolution of bodies: Notes on the relationships between plants and humans}

\begin{abstract}
This text addresses the relationship between the domestication of plants and the disorder that has been established as a result of the current pandemic. This is done by considering the poetics of hybridisation, a policy of dependence and the care generated by the practice of vegetable grafting. In addition, it discusses the history of and search for other forms of conception and enunciation of the body and the environment in the context and thinking of native peoples, in particular the notion of - and Otomi word - Nzaki, "tree of blood", which is taken as a discursive and artistic exploration on the search for new relatives to domestic plants.
\end{abstract}

\section{Keywords}

Saintpaulia, Huernia, vegetable graftings, evolution, body, decolonial, Nzaki.

\section{Un desorden establecido}

¿Cómo darle significado a un mundo pandémico que hoy se nos presenta sin sentido? No hay una respuesta cierta 0 una fórmula para transitar a un mundo pospandemia, pero contamos con la posibilidad de reinventar las imaginaciones y nuestras interacciones con lo viviente y sus misterios. Para ello, este texto propone habitar la experiencia del distanciamiento social y el confinamiento como parte de un correlato sobre la domesticación de las especies. El énfasis que se hace sobre las relaciones vegeto-humano desde una histórica de las plantas atiende a establecer que la crisis radicalizada por la pandemia, que vivimos diferencialmente entre continentes, países, ciudades y pueblos, tiene su base en las historias y la perpetuación de relaciones coloniales y neocoloniales del paradigma del progreso, impuestas por los países de economías hegemónicas.

La pregunta clave es: ¿qué implica para nuestras vidas urbanas la domesticación de la tierra y las plantas como un capítulo importante en los procesos evolutivos tanto socio-culturales como biológicos? Es una pregunta que asume que los tiempos de pandemia son una experiencia radical de laboratorios sociales de nuestra cultura neoliberal.

Las notas, reflexiones e imágenes que se presentan en este texto son parte de un proceso de observación, exploración y documentación artística sobre la reproducción y el crecimiento de especies como la Saintpaulia y la Huernia Schneideriana, dos plantas con flores de la familia de las Gesneriaceae y de las Apocynaceae, es decir, se localizan en las zonas tropicales y subtropicales. Ambas se han convertido en plantas de ornato con una alta producción en invernadero en todo el mundo. Particularmente, la Saintpaulia es considerada una «planta panda», es decir, un síntoma de la devastación de la zona tropical africana (Eastwood y otros, 1998).

En este sentido, se reflexiona estéticamente sobre la propagación vegetativa mediante injertos y su relación con la manipulación y los límites e implicaciones de una poética de la hibridez vegetohumana en el marco de un debate crítico de la domesticación y convivencia interespecies. La experiencia global de confinamiento y la casa como un hábitat se pone en el centro de nuestra reflexión, porque tiene un despliegue sistemático que afecta el «derecho» a la movilidad, local y transnacional, ya que existe un cierre radical y violento de fronteras, lo que ha parado tajantemente las migraciones e inmigraciones del sur al norte por pobreza, desempleo y violencia de los países de la periferia económica. Al mismo tiempo, nos obliga a repensar nuestras relaciones con la experiencia de la vida y las normativas de control que paradójica y confusamente ponen en juego una política del cuidado. En otras palabras, la domesticación es un juego de control y cuidado, de dependencia y productividad, de seguridad y vulnerabilidad.

Acaso entonces ¿hemos sido «humanos... demasiado humanos»? Es decir, llegamos a la expresión más clara de nuestros regímenes extractivistas y vivimos las consecuencias del triunfo de la mundialización de la guerra de conquista que ha garantizado la sobreexplotación y expropiación de lo viviente y de la materia inerte que la filosofía y la ciencia coloniales definieron y redujeron a recursos naturales y fuerza de trabajo.

La condición de «inmovilidad» hoy se expande a las personas que viven en hacinamiento, desempleo y empleos precarizados, campo de cultivo para la violencia familiar y de género. Pero, también, marca la movilidad por despojo en las ciudades y la ausencia de una casa en la cual resguardarse, focalizando la exacerbación de los llamados sintecho y desplazados; para una y otra dirección, el universo de lo doméstico expone problemáticas epistemológicas, políticas, éticas, estéticas de lenguaje en un mundo pospandemia donde se disputa la vida.

Héctor Abad Gómez (2012), en su texto Fundamentos éticos de la Salud Pública, afirma que «los virus, bacterias, parásitos, ratas y hombres son materia viva disputando materia inerte para nuestra multiplicación y supervivencia como especie». La idea privativa de 


\section{artnodes}

lucha, y no de colaboración y mutualismo por la materia, es el resultado de la invención de la supremacía entre cultura y «naturaleza», ciencia $y$ «creencias», que no son otra cosa que los constructos coloniales de civilización y primitivismo que justifican todas las medidas implementadas para alcanzar un estado de «progreso» y capitalismo tecnológico e instrumental de la ciencia y el desarrollo como horizontes aspiracionales de los Estados-nación.

Este violento impasse ha traído la urgencia de repensarnos en lo individual, pero sobre todo en lo colectivo, reconociendo el territorio y las memorias ocluidas por las historias y los conocimientos hegemónicos y coloniales.

¿Cómo imaginar estos «sentir-pensares», dirían los grupos zapatistas del sureste mexicano, desde la tierra hasta nuestros cuerpos y las relaciones de la vida más allá del antropocentrismo? ¿Con qué tipo de prácticas, memorias y organización contamos para crear experiencias más allá de la tecnología que se define en los marcos de la modernidad y el progreso universal?

Uno de los abrevaderos a los cuales recurrir son las comunidades de pueblos originarios del mundo como los mayas o los quechuas de los Andes, quienes hoy siguen luchando por mantener otras prácticas y relaciones entre la tierra y lo humano a través de formas de interacción ritual-simbólica que conlleva procesos de sustentabilidad, esa ecología que integra la administración de la energía interespecies con la materia orgánica. ¿Cuáles son los riesgos de voltear nuestras miradas a esos otros saberes? Desde mi punto de vista como activista social y artista, el mayor riesgo es entrar a esos universos desde la idealización, la ingenuidad y la dependencia epistémica, actitudes y prácticas que facilitan la repetición de la historia de la conquista por esos «nuevos mundos» $\mathrm{y}$ «paraísos perdidos».

En los marcos de la crítica y nuestros lenguajes ordenados de la academia, hay autores que han puesto en cuestión los paradigmas de nuestro humanismo racional-utilitario desde un ejercicio decolonial, es decir, tomando un cúmulo de experiencias y teorías de y en la academia latinoamericana, que continúan en la circulación de las diversas industrias teóricas. A mi consideración difieren de una práctica anticolonial, es decir, si seguimos el trabajo de Franz Fanón y la noción de blanquitud de Bolívar Echeverría, la anti-colonialidad es un ejercicio que no negocia desde ningún ángulo con los procesos de colonización-y neocololización-, ya que si desde los colonizados se establecen mediaciones en beneficio de grupos o discursos particulares, se da pauta al quiebre del bien común; por tanto, la colonización externa muta a procesos internos de mayor arraigo, porque se configuran desde el corazón de la cultura, el mestizaje de símbolos y la dependencia epistémica desde la propia autoenunciación, fortaleciendo a los sujetos racializados y definidos como colonizados, pero que ostentan la representatividad del poder del colonizador, una especie de suplantación.

Las prácticas anticoloniales aspiran a estar fuera de los lugares de circulación del sistema de las industrias intelectuales y expandirse en el ejercicio particular, situado y transfronterizo de la experiencia local, cotidiana que integre en el cuerpo el pensamiento, la inminencia del entorno y de lo común.

Pese a que se ha dicho mucho sobre la necesidad de modificar nuestros paradigmas y valores modernos y de progreso, no ha sido suficiente para producir una ruptura radical de la subjetividad moderna que nos permita ejercer la existencia de otros mundos posibles. Cuando hablamos de la interacción entre especies y materias biológicas, el ser humano interactúa desde una condición de control y supremacía con todo, aun sabiendo que a nivel biológico no somos nada especial (Briones, 2019).

\section{El cuento del cuerpo, el pez y la flor}

La enunciación hegemónica del cuerpo humano es una entidad históricamente estructurada a partir de formulaciones de la mirada y la tecnología científica. La evolución, la genética y la anatomía se han interconectado para clasificar los cuerpos desde su normalización biológica y anatómica. El sistema de normalidad del cómo debemos representarnos y vivir nuestros cuerpos (género, raza, clase, etc.) simultáneamente crea los mecanismos de marginación de «lo anormal», que en su momento se circunscribieron a la teratología o ciencia que estudia a los monstruos. Desde esta perspectiva, los monstruos se explicaron en la incertidumbre de la anomalía genética que rompió con la línea mítica e histórica de los seres híbridos animal-humano, planta-humano, mineral-humano.

Pero hay otras culturas donde el imaginario de la fragmentación no necesariamente distancia el cuerpo del mundo, sino al contrario. En la cultura otomí del centro de México, el cuerpo tiene tres desdoblamientos de sentido y enunciaciones: ma ndo'yo, «mi cuerpo», al mismo tiempo significa «piedra que camina», haciendo referencia a Ios huesos y el movimiento del cuerpo; ngokei o «carne de persona», que refiere a la masa muscular, a la abundancia, al bienestar y a la alegría; finalmente $x i$ se traduce como «piel», que no solo corresponde a la epidermis humana, sino a distintas pieles como la «piel suprema que envuelve el mundo», ximhoi, que significa «piel de la tierra». En este sentido, es entre estos intersticios donde el cuerpo se extiende, que también es otro significado de $x i$, y se ejerce como una fuerza en permanente movilidad y flujo (Gómez, 2019).

Pese al imaginario híbrido, nuestro linaje, según Charles Darwin, está emparentado al de los mamíferos, particularmente de los primates; esa es la ruta más común del rastreo de la historia de nuestros cuerpos que decanta en la evolución de la liberación de las manos. Liberación que nos induce a la subjetividad civilizatoria del bipedismo y del trabajo, pero al mismo tiempo, es el punto de diversificación para encontrar otras ascendencias en nuestra historia. El paleontólogo Neil Shubin explica la conexión evolutiva del cuerpo a partir de los peces, cuyos fósiles muestran que son las primeras criaturas que presentan esqueletos óseos como los nuestros. Su estructura de espina dorsal y cráneo establece ese común denominador (Shubin, 2014). 


\section{artnodes}

En esta deriva de la evolución del pez 0xana Timofeeva propone una dialéctica del pez desde una relación animales, proletariado y comunismo (Timofeeva, 2018: 134). Particularmente, me interesa resaltar la problemática de la inmanencia como una relación imposible entre los seres y su medio. Es decir, en la relación intrínseca del medio, donde se establecen las interacciones, el pez es al agua tanto como el agua es a la vida de una comunidad acuática. Suponemos que las condiciones de existencia, el modo de vida y las actividades definen intrínsecamente a los seres con su medio y viceversa, creando un cuidado mutuo; no obstante, en los procesos evolutivos un tipo de peces deja el agua para adentrarse en el medio terrestre, estableciendo otras condiciones y cambiando en sí mismo para adaptarse a otro medio, como el propio Shubin lo narra. Sin embargo, el ser humano, a partir de su mentalidad del progreso y la modernidad donde agua y pez se vuelven recursos al servicio de las industrias, no lleva precisamente a la evolución de los peces, sino a su extinción y contaminación de las aguas. Ante tal situación podría surgir una particular revolución de los peces, criaturas acuáticas levantándose para defender su medio y a sí mismas.

¿A quién le corresponde esa revolución? Timofeeva infiere que al proletariado a partir de la ruptura de sus propios límites con otras criaturas, si la inminencia tanto como la revolución se inscriben en lo imposible porque nunca serán absolutas, ni estables, ni acabadas, se hace necesario ampliar las imaginaciones hacia las multitudes de criaturas. Crear empatía por rescatar al mundo a partir de prácticas para reconstruir nuestras mentalidades y construcciones simbólicas, Donna Haraway propone reinscribirnos con otros parentescos, más allá de la genética. Una revuelta de criaturas que rompen los límites de sí mismas y se desdoblan en otroas (SubGaleano, 2020).

Sin embargo, las imaginaciones que hegemonizan todavía nuestras relaciones con lo vegetal se sustentan en los rastros históricos y sociales modernos vinculados a la agricultura y a la domesticación; de esta manera, encontramos que la complejidad de parentescos de lo humano está desligada de la ontogenia vegetal. Quizá este distanciamiento se deba a la falta de asociaciones anatómicas en las bases de la filosofía aristotélica. El libro Investigación sobre los animales es una anatomía comparada, donde animales y humanos somos nombrados y comparados mediante algunos órganos; así, el corazón es un órgano unitario que, si bien en el hombre no se encuentra en el centro, sino a la izquierda del pecho (Aristóteles, 2008: 76), sigue siendo la familiaridad orgánica que sistemáticamente no sucede con las plantas.

El estudio y los hallazgos sobre la evolución de las plantas comienzan en la segunda mitad del siglo xx (Moreno, 2002); para algunos científicos ha representado un desafío, debido a la escasez de registros fósiles, particularmente del origen de las angiospermas o plantas con flores. Esta especie estableció interacciones simbióticas a partir de los procesos de polinización y ha dado origen a los ecosistemas actuales (Magallón, 2020), es decir, sin las flores no tendríamos los biomas que conocemos. De esta manera, podemos entender que la importancia que tienen las plantas está más allá de las fronteras de la agroindustria. Alexander Von Humboldt planteaba que la geografía de las plantas no radicaba en su clasificación o disección morfológica, o en encontrar nuevas especies, sino en observar y entender las relaciones con el entorno y sus diversos componentes. En este sentido y más allá de nuestras referencias de las ciencias y la filosofía occidental, las plantas forman parte de complejos usos del lenguaje y prácticas del cuerpo que aparecen en relatos, leyendas, recetas, rituales (Olavarría, Aguilar y Merino, 2009: 5) encarnadas en el cuerpo mediante relaciones desde sus propiedades, partes, funciones, formas, etc.

El cuerpo-planta aparece en las cosmogonías y en el lenguaje de grupos étnicos de América Latina, Australia, incluso en Europa en la Edad Media, donde se concebía como un microcosmos que reproducía el macrocosmos universal bajo el signo de la trascendencia cristiana (González, 2006: 54). Francisco González Crussí, médico especializado en anatomía patológica, narra que los kanaks, grupo étnico al noroeste de Australia, hablan del cuerpo como si se refirieran al reino vegetal: kara para nombrar la corteza de un árbol y la piel corporal, pié para la carne, los músculos, igual que la pulpa de las frutas.

En la lengua quechua también encontramos esta fusión del cuerpo con las plantas y la tierra. Pullu es pelo o vello de personas 0 aves, a su vez, es la raíz del término pullullulluni que significa «herir la olla o manar el agua», mientras que Ilullu es «pimpollo de árbol blando, o cosa blanda assí». «llullun, los tallos o hojas tiernas, verdes antes de endurecerse». Los cabellos, entonces, son vellos que emanan 0 brotan, pero también estos pelos son hojas o tallos tiernos de los árboles (Díaz, 2016: 154).

De esta manera, los procesos de borramiento de fronteras entre lo vegetal y lo humano se inscriben en el lenguaje desde la operación simbólica, poética y ritual; no obstante, la inmanencia entre planta, territorio y humano se confiere a una estructura reguladora de los saberes de las hierbas y flores, que para el historiador mexicano Miguel León-Portilla pueden considerarse proto-científicos, (Rojo, 2020: 9). Pero más allá de su legitimidad científica, en el pueblo yaqui asentado en Sonora en México, el término «cuerpo flor» o seewa takaa es un intermediario capaz de influir sobre el entorno, es decir, un mecanismo de la inmanencia dada a los seres que «pertenecen al monte». Donde el monte se identifica como el «hogar precristiano» de los yaquis que atraviesa un proceso de resignificación y permanencia mediante rituales realizados por personas que son danzantes, músicos, curanderos, parteras, hechiceros, entre otros.

En el contexto de los discursos de progresión evolutiva del conocimiento, donde la meta es la comprensión racional de los fenómenos relacionados con el cuerpo y la frontera de lo indómito, que en su caso es lo que hemos denominado e identificado como «naturaleza» - un 


\section{artnodes}

espacio más de la imposibilidad, (Haraway, 1999)-, el desafío radica más allá de la enunciación, es decir, hay una condición de experiencia que no necesariamente pasa por la gramática del castellano y la ideología de la ciencia moderna, sino por una experiencia no enunciable que rebasa las normas de las clasificaciones, que se concentra en el movimiento, la oralidad, la observación pausada, la lentitud del crecimiento que no es perceptible a simple vista.

Ante estas posibilidades, la pregunta obligada es si la llamada ciencia moderna y el cúmulo de conocimientos y tecnologías hasta ahora conocidos corren el riesgo de «sufrir un retroceso» hacia prácticas «mágicas» y «atávicas». ¿La magia es verosímil porque la ciencia perdió su efecto liberador? El uso mecanicista que ha derivado en la explotación de territorios y materia orgánica humana y no humana en beneficio del progreso científico es un paso al desencanto de un sistema de expropiación permanente; en este sentido, el discurso de la ciencia también perdió la capacidad sensible de las poéticas de la creación, o la experiencia envuelta en el ciclo de la transformación de la vida.

El «devenir con» (Haraway, 2019) planta o flor, así como el «devenir con» pez son universos por demás complejos donde no existen las categorías de género y raza, no hay sujetos mujeres atadas a una biología específica, porque lo que se produce son ciclos simbióticos entre distintos reinos vegetales, animales y microbios. Tampoco somos cuerpos-máquinas con funciones específicas fragmentadas, sino una fuerza liberadora de movimiento que ocupa el espacio, la dirección y la luz. Las plantas y las flores están más allá de anatomías mecánicas como respuestas a su propagación por el mundo. A la par de sus particulares formas, ellas se expanden por los estímulos e impulsos. Son más bien poéticas de tiempos ancestrales que no somos capaces de percibir, expresar y tampoco de enunciar bajo la gramática actual de la ciencia moderna, y quizá tampoco con nuestro vocabulario limitado a ciertos conceptos derivados de idiomas e ideologías hegemónicas.

Ahora bien, ¿qué sucede con las prácticas creativas e imaginativas inscritas en las artes? ¿Acaso y pese a sus propios esfuerzos las artes también están en la misma crisis de las ciencias? ¿Quizá en el mismo ejercicio de reflexión también vaya incluida la crítica a la autorreferencialidad del arte y del artista como parte del mismo modelo que exacerba las tendencias «biomediales» y banaliza la complejidad de lo que se ha llamado por contraste biotemática? (López del Rincón y Cirlot, 2013). En esta coyuntura de saberes entre ciencias y artes valdría la pena revisar críticamente la pertinencia de los presupuestos del paradigma emergente del conocimiento científico que propone Boaventura de Sousa Santos: a) todo conocimiento científico es autoconocimiento; b) los sistemas de creencias, los juicios de valor no son antes ni después de la explicación científica 0 las sociedades, son parte integrante de esa explicación; c) un conocimiento científico que más que controlar al mundo ha de crear experiencias estéticas y de contemplación; y d) el desarrollo tecnológico debe traducirse en sabiduría de vida (Sousa, 1990).

\section{Breve nota sobre injertos y domesticación en el arte}

El injerto es un procedimiento de propagación vegetativa vinculado a la domesticación y a la multiplicación de plantas en horticultura y agricultura, fundamentalmente plantas comestibles y de ornato. EI verbo injertar radica en la práctica humana de generar las condiciones para que este tipo de multiplicación se lleve a cabo; sin embargo, si lo pensamos desde la planta, es la capacidad del «tejido herbáceo, cuando es análogo, de soldarse 0 unirse del mismo modo que los tejidos animales en la cicatrización de las heridas» (Boutelou, 2007).

De esta manera, sistemáticamente no hay seres de distintas naturalezas que puedan injertarse; de lo contrario, crearíamos monstruos que alterarían el orden establecido. La anulación de este principio de paridad en las artes a veces atiende a una poética de la hibridación que tiene como fin transgredir la normalidad hegemónica y mostrarnos un universo donde somos materia orgánica interconectada entre sí.

En el pasaje histórico del bioarte, particularmente de lo que Eduardo Kac Ilamó arte transgénico, los cuerpos son un lugar de transmutación continua extendiéndose más allá de la piel. De esta manera, la ingeniería genética se vuelve un mecanismo de expansión interespecies que se debate en la experiencia estéticopolítica -a mi modo ver, ético-histórica que tendría que colocar en la estructura artística el debate de prácticas decoloniales y, ya en una reflexión más profunda, imaginaciones anticoloniales-. En el epicentro bio-medial la intervención de la ingeniería genética en las artes crea organismos vivientes singulares, como es el caso de Edunia, un híbrido con información genética de Kac en una petunia, la cual expresa su ADN en las venas rojas de la flor (2003-2008). En el seguimiento de estas prácticas transgénicas se expone las relaciones de control y cuidado de una domesticación radical mediante ingeniería genética, Kac escribió que el GFP-9, un perro con pelo (1998) fluorescente, sería un miembro bienvenido a su familia, porque la responsabilidad de crear estas criaturas singulares implica su cuidado. Las semillas de la Eduina eran regaladas al público para que las sembrara y cuidara.

En aquel momento, esta perspectiva vida-tecnología fue innovadora apelando a un tipo de encarnación cuerpo-tecnología biológica; sin embargo, hoy tenemos la obligación de debatir la idea de que la tecnología nos hará libres y podrá resolver las contradicciones que han generado la modernidad y el capitalismo.

Donna Haraway, hacedora del Manifiesto Cyborg (1983), ha autorrefutado las relaciones cuerpo-máquina en contraste con su Manifiesto de las especies de compañía, perros, gentes y otredad significativa (2003). Su propuesta es construir nuevos relatos en un participio pasado, emergente e inacabado. Historias activas que cohabitan relaciones polimorfas y agenciamientos interespecies que permitan trazar otros parentescos. Asimismo, estas historias 


\section{artnodes}

https://artnodes.uoc.edu

Imaginaciones de la evolución de los cuerpos: apuntes sobre las relaciones entre plantas y humanos

están enclavadas en la experiencia de la «lengua» que se escapa de la estructura gramatical del idioma y emerge como actos del cuerpo que están en permanente cambio, siempre viajando para variar de significado. Sería una rebelión de los símbolos o una revuelta contra los símbolos que perpetúan la binariedad, la patriarcaización, la racialización y la división clasista del capitalismo.

El centro de la cohabitación de Haraway es un giro al mito de la evolución darwiniana, un paso más adelante para encontramos con la simbiosis como fuerza evolutiva, la cual «no acepta el concepto de competencia ni de organismos más evolucionados que otros» (Margullis y Sagan, 2002). Además de comprender que la capacidad de mutación frente a los cambios se realiza mediante la cooperación y mutualidad entre formas de vida, en este escenario podemos ver que la domesticación de especies crea panoramas de dependencia, control y poder en beneficio de la productividad de las especies. Generalmente, se ha empleado bajo un sistema de cuidados que busca que la especie domesticada pierda atributos para mutar y crear, o mantener la unión con distintos organismos y estrategias para formar nuevas colectividades y sobrevivir a los cambios.

\section{Apuntes para un cuento sobre el flujo de Nzaki y mi parentesco con las plantas}

\section{Nota 1. Sobre el movimiento y la energía}

Si el alimento les falta, languidecen; experimenté el sentimiento doloroso del hambre y el placer de la satisfacción del paso del tiempo en el crecimiento y la transformación de sus vellosidades, pero también en su permanencia fragmentaria, casi ascética, después de secarse. Es ahí que mi «árbol de sangre» o Nzaki se extiende hacia la savia, pero todavía estoy descifrando la lengua, las imaginaciones de ese flujo vital que los otomíes nos atribuyen a todo lo viviente y a la movilidad misma de nuestra fisicalidad.

Mientras el cuerpo que conozco se traduce como un aparato de la física, un detector químico que entra y sale del cuerpo de carne, el Nzakise vive como un flujo de energía siempre expuesta a debilitarse, aumentar o perderse y reflejarse en la materia misma.

Uno de los grandes misterios de las plantas es el tiempo y e movimiento, un código que quizá traducimos más en la física y en la neurología y menos en la botánica o la anatomía; sin embargo, los estudios de las plantas se han extendido a la neurobiología vegetal y a la biología cuántica, que, por un lado, nos llevan a universos de lenguaje y observaciones más amplias, pero, paradójicamente, más especializadas y menos accesibles al cotidiano.

En la dependencia de mis cuidados y el control parcial de su multiplicación, mis plantas domésticas son una compañía que disputa el movimiento como lo conozco y pone en cuestión la condición sésil que se les atribuye.
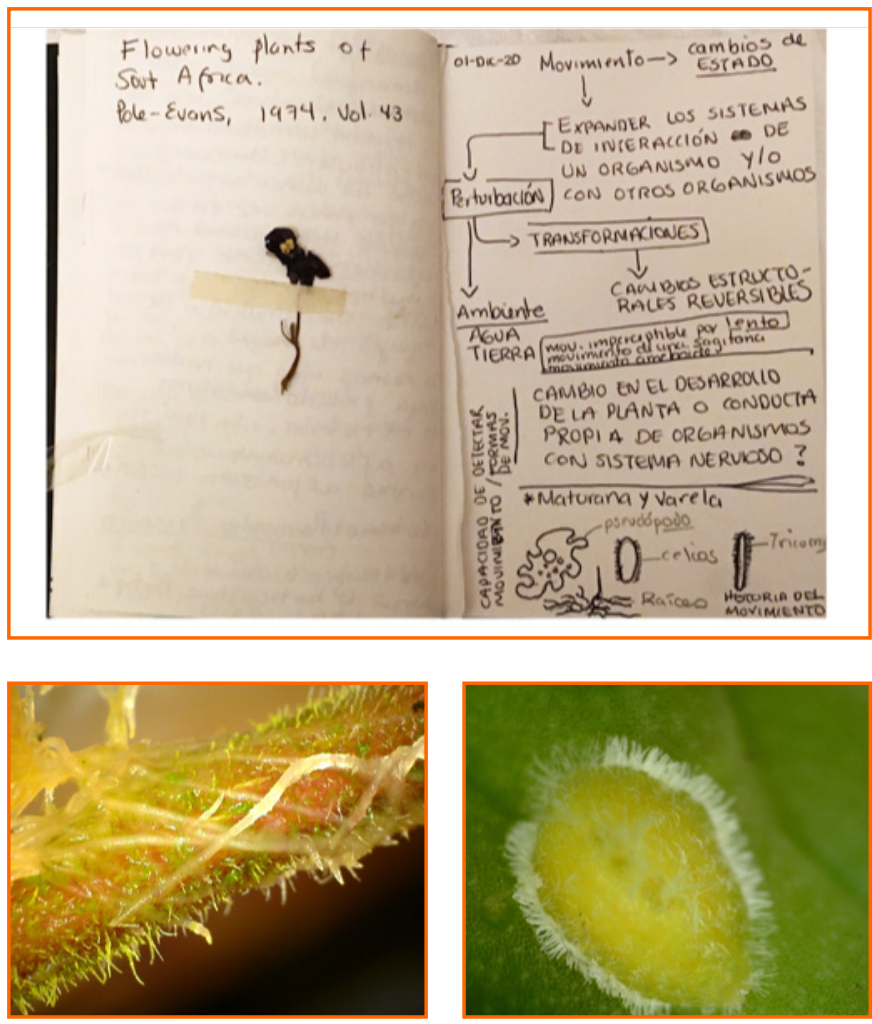

Bitácora. Notas sobre vellosidades, raíces y movimiento. Arriba: diagrama sobre movimiento a partir del segmento «Historia natural del movimiento». Abajo dcha.: crecimiento de raíces y vellosidades del tallo de una Saintpaulia en el proceso de multiplicación por esqueje (otra forma de injerto). Izq.: parásito (probablemente Planococcus citri o Pseudococcus citri) de la Huernia Schneideriana. México, 2020.

\section{Nota 2. Sobre las interferencias de la historia}

Me pregunto si estos pasajes en gris acerca de lo indómito de las plantas y la maraña de energía de los cuerpos pueden percibirse con el desarrollo del Nzaki. ¿Este desdoblamiento de los cuerpos en energía necesita de la vista o de la historia? ¿Cómo desarrollar el Nzaki? Los otomíes visualizan y viven varios tipos de cuerpos: otro de ellos es el Mfeni, asociado al pensamiento y al pasado. Una traducción es el cuerpo que se entiende por lo aprendido a lo largo de su historia (Gómez, 2019).

Es así que, al extender los hilos de mi familia en el universo de lo doméstico, rastreé la historia de Saintpaulia, y es una extensión de los procesos de colonialidad y explotación de África. En este punto, hay una limitante de traducción sobre el horizonte de significado del Mfeni, debido a que la traducción indica que se refiere al acto específico de pensar, el «dolor del pensamiento», que probablemente no está asociado a las plantas; sin embargo, el Mfeni afecta directamente al Nzaki, entonces es posible atribuir esta marca del pasado a la Saintpaulia. Con cuidado de no ejercer una traducción e interpretación antropocéntrica, se aclara que cuando se habla de domesticación no solo nos referimos a cuerpos humanos, sino a la materia orgánica que ha sido cosificada 


\section{artnodes}

https://artnodes.uoc.edu

Imaginaciones de la evolución de los cuerpos: apuntes sobre las relaciones entre plantas y humanos

y explotada en beneficio de una sola especie, limitando su movilidad y atrofiando su desarrollo de propagación y mutualidad simbiótica.

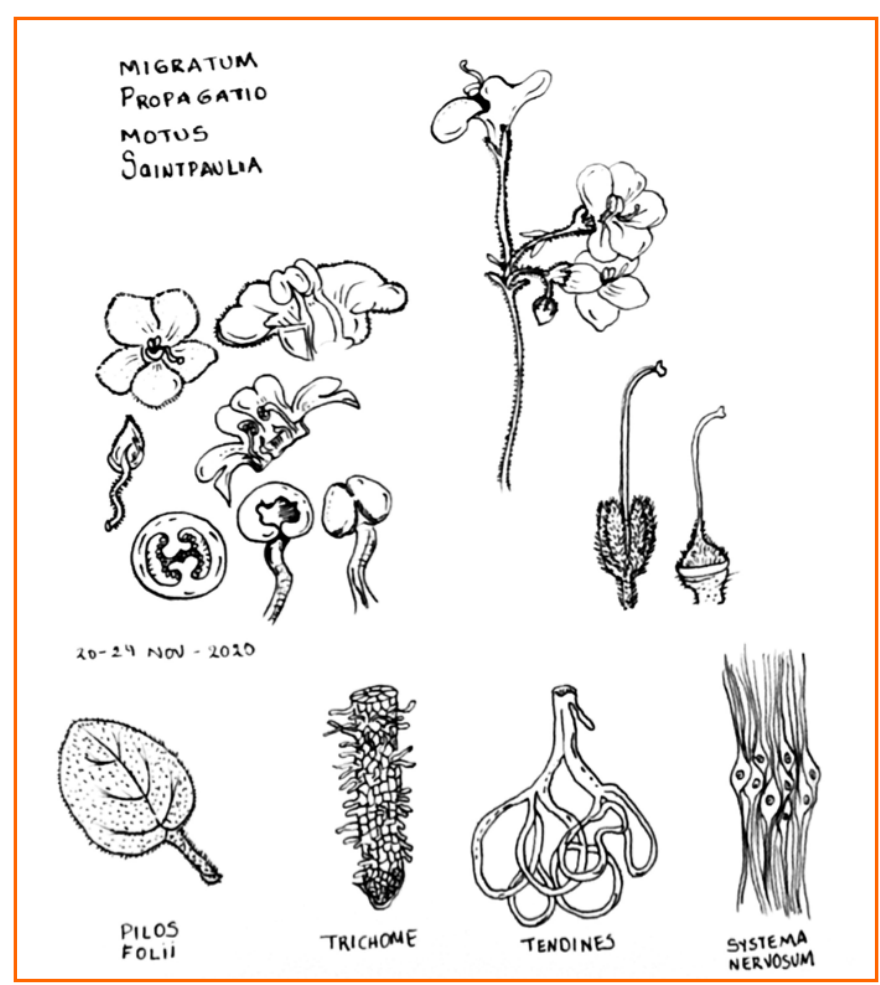

Bitácora. Notas sobre la transformación y la anatomía botánica: interrupciones del archivo. llustración que modifica la reproducción de la Saintpaiulia ionantha en la Revista Curtis's Botánical de 1895. México, 2020.

La Saintpaulia y quizá más recientemente varios tipos de suculentas, entre ellas la Huernia, son «plantas panda», es decir, un síntoma encarnado de la extinción de especies vegetales que crecían en la zona tropical de África, fundamentalmente en Tanzania. Clasificar y nombrar es parte constitutiva de nuestra historia civilizatoria a través del lenguaje, nos desciframos e identificamos por medio del nombre, que en este caso es el archivo colonial que instituye la práctica domesticadora de la Saintpaulia, nombrada así por el barón Walter Von Saint Paulillaire en 1893. También se tiene registro de que el «Sr. Hermann Wendland de Herrenliausen de Hannover la mostró por primera vez en la Exposición Internacional de Horticultura de Gante en 1899, donde se la conoció como "violeta del Usambara", zona donde se tiene registro de que existían la mayor parte de especies. Para los horticultores es una de las "plantas de invernadero" más bonitas que no se ha probado su multiplicación para crecer en exterior en zona rocosa como su hábitat original». (Journal D’Horticulture, 1901).

\section{Nota 3. La poética de los híbridos}

La Huernia y yo experimentamos el debilitamiento energético del Nzaki, al mismo tiempo que mi sistema inmunológico decayó por un virus, los tallos de ella comenzaron a cambiar de verde a amarillo de la punta a la base, falta de nutrientes y posible infección por un parásito que inoculó un virus. Ambos cuerpos, ambas energías debilitadas. Era necesario pensar en el injerto como un mecanismo de sobrevivencia. ¿Quién iba a ser el portainjerto?, es decir, ¿quién iba a cancelar toda posibilidad de crecimiento y multiplicación para convertirse en receptáculo o macetero vivo de la otra?

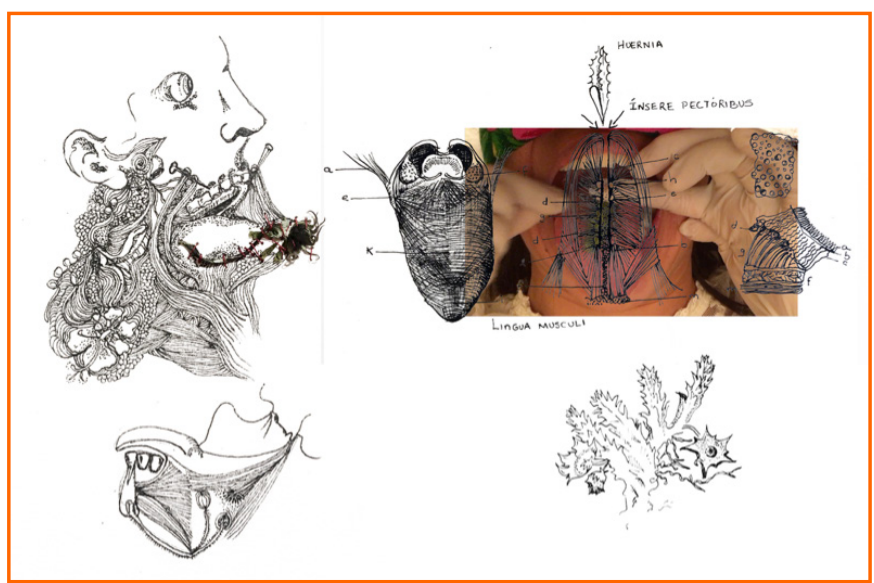

Bitácora. La lengua como receptáculo del esqueje de la Huernia. Objetivo: crear una interferencia con el lenguaje para recuperar y, al mismo tiempo, expandir la energía del Nzaki. México; 2020.

\section{Referencias bibliográficas}

Abad Gómez, Héctor. 2012. Fundamentos éticos de la Salud Pública. Medellín. Universidad de Antioquia, 1987.

Aguilar, Cristina, Erica Merino, y María Eugenia Olavarría. 2009. El cuerpo flor. Etnografía de una noción yoebe, México: Porrúa-UAM.

Darwin, Charles. 1979. «Variación del estado doméstico» y «Variación en el estado de naturaleza». El origen de las especies. México: Editorial Diana: 24-75.

Darwin, Charles. 1881. The power of movement in plants. New York: D. Appleton and Company. DOI: https://doi.org/10.5962/bhl. title.102319

Boutelou, Claudio. 2007. Tratado del injerto, Andalucía: Consejería de Agricultura y Pesca, (Colección: El Arado y la Red).

Díaz, Carla. 2016. «Cuerpo vegetal y violencia fecundadora en las fuentes coloniales andinas». Boletín del Museo Chileno de Arte Precolombino 21(2): 153-169. D0I: https://doi.org/10.4067/ S0718-68942016000200010.

Echeverría, Bolívar. 2011. «Imágenes de la blanquitud». en Modernidad y blanquitud. México: Biblioteca Era: 57-86.

Eastwood, A., Bytebier, H., Tye A., Robertson A. y Maunder M. 1998. «The conservation status of Saintpaulia». Curtis and apos's Botanical Magazine 15(1): 49-62. D0l: https://doi.org/10.1111/14678748.00132 . 


\section{artnodes}

https://artnodes.uoc.edu

Imaginaciones de la evolución de los cuerpos: apuntes sobre las relaciones entre plantas y humanos

Gómez, Sánchez, Davis. 2019. «El cuerpo, un análisis desde la lengua y la cultura otomí». Revista peruana de antropología 4(5), Abril 2019.

González Casanova, Pablo. 2006. «El colonialismo interno». Sociología de la explotación. Buenos Aires: CLACSO: 185-205.

González Crussi, Francisco. 2006. La fábrica del cuerpo. México: Los Cuadernos de Quiron.

Haraway, Donna. 1991. Ciencia, cyborgs y mujeres. La reinvención de la naturaleza. Madrid: Cátedra.

Haraway, Donna. 1999. «La promesa de los monstruos: una política regeneradora para otros inapropiados/bles». Política y Sociedad 30.

Haraway, Donna. 2017. Manifiesto de las especies de compañía. Perros, gentes y otredad significativa, Córdoba (Argentina): Boca Vulvaria Ediciones.

Haraway, Donna. 2019. Seguir con el problema. Generar parentesco en el Chthuluceno, Bilbao: Consonni.

López del Rincón, Daniel, y Lourdes Cirlot. 1999. «Historiando el bioarte 0 retos metodológicos de historia del arte (de los medios)». En Pau Alsina (coord.). «Historia(s) del arte de los medios». Artnodes 13: 62-71. DOI: https://doi.org/10.7238/a.v0i13.1999.

Maeterlink, Maurice. 2015. La inteligencia de las flores. Buenos Aires: Interzona.

Maturana R., Humberto, y Francisco Varela G. 2003. «Sistema nervioso y conocimiento». En El árbol del conocimiento. Buenos Aires: Lumen: 97-117.

Revue horticulture, Journal D'Horticulture Practique. París: 1901.

Rivera Cusicanqui, Silvia. 2015. Sociología de la imagen. Miradas Ch'ixi desde la historia andina. Buenos Aires: Tinta Limón.

Pulpillo, Araceli, y Mayra Citlalli Rojo Gómez. 2020. «Sanadoras: Historia Colectiva de Mujeres en Resistencia». Labio Asesino Fanzine 4: 8-12.
Sousa de Santos, Boaventura. 2015. «Un discurso sobre las ciencias». En Construyendo las epistemologías del Sur. Buenos Aires: CLACSO-Siglo XXI: 17-59.

Stavenhagen, Rodolfo. 1981. «Siete tesis equivocadas sobre América Latina». En Sociología y Subdesarrollo. México: Nuestro Tiempo: 15-84.

SubGaleano. 2020. «La mirada y la distancia a la puerta». Comunicado Quinta Parte, Octubre 2020. https://enlacezapatista.ezln.org. mx/2020/10/09/quinta-parte-la-mirada-y-la-distancia-a-la-puerta/.

Timofeeva, Oxana. 2018. The history of animals. A philosophy. Gran Bretaña: Bloomsbury Academic.

\section{Vídeo}

Briones Llorente, Carlos. 2019. «El origen de la vida y su búsqueda fuera de la tierra». Coffeeversity, Universidad de Granada, vídeo, 2:08:05. https://www.youtube.com/watch?v=4Dsgz7f71SY.

Magallón Puebla, Susana. 2017. «Origen y evolución de las platas con flores». Los viernes de la evolución, 2017, 1.a sesión, El Colegio Nacional, vídeo, 1:21:30. https://www.youtube.com/ watch? $v=c 5 Q j o e 0 X E d 0$.

Magallón Puebla, Susana. 2020. «La edad de las plantas con flor». Ciclo Universidades por la ciencia, El Colegio Nacional, vídeo, 1:58:50. https://www.youtube.com/watch?v=MLLDw48Mgj4.

Margullis, Lynn, y Dorion Sagan. 2002. «Los saltos de la evolución. Entrevista a Lynn Margullis y Dorion Sagan». Entrevista de Eduard Punset en Redes. RTVE, 2002, víde0, 54:56. https://www.rtve.es/ alacarta/videos/redes/redes-saltos-evolucion/2359188/.

Shubin, Neil. 2014. «Tu pez interior», por Windfall Films, Tangled Bank, vídeo, 54:41. https:// www.youtube.com/watch?v=7N4aYPviFTM. 


\section{artnodes}

https://artnodes.uoc.edu

Imaginaciones de la evolución de los cuerpos: apuntes sobre las relaciones entre plantas y humanos

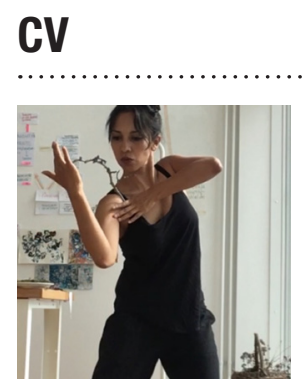

\section{Mayra Citlalli Rojo Gómez}

Artista-investigadora independiente

mayracitlally@gmail.com

Artista mexicana, investigadora interdisciplinaria y curadora en artes visuales y discursos del cuerpo. Llevó a cabo una investigación postdoctoral sobre textil y celulosa bacteriana. Sus ejes de investigación artística y teórica son los discursos del cuerpo y la teratología, el origen de la vida desde lo que ha llamado anatomía- botánica y tejidos liminales. Más: https://mayracitlally.wixsite.com/mayra-rojoartdesign 